\title{
Relações Internacionais do Mundo Árabe (1954-2004): Os Desafios para a Realização da Utopía Pan-arabista*
}

\section{Silvia Ferabolli*}

Desde a formação do Sistema Árabe de Estados, na esteira do processo de descolonização, a retórica nacionalista árabe, ou pan-arabista, tem sido o pano de fundo sobre o qual as relações políticas intra-árabes se desenvolveram. ${ }^{1}$

A crença básica que subjaz ao discurso pan-arabista é a de que todos os árabes, como uma comunidade imaginada, compartilhariam a mesma língua, cultura e história, e que, por isso, deveriam unir-se em um único Estado-nação, sob um governo central, formando a tão sonhada "Grande Nação Árabe".

Contudo, as relações entre os Estados que formam aquilo que se denomina "Mundo Árabe" sempre estiveram muito aquém da unidade, tendo se caracterizado mais pela desintegração.

*Artigo recebido em maio e aprovado para publicação em julho de 2006.

**Mestre em Relações Internacionais pela Universidade Federal do Rio Grande do Sul (UFRGS) e professora de Ciência Política e Relações Internacionais da Faculdade Montserrat de Caxias do Sul. 
Apesar do fracasso das ideologias pan-arabistas para promover a unidade regional, repetidos esforços têm sido feitos para alcançar alguma medida de integração ou, pelo menos, de coordenação política e/ou econômica.

Os esforços da Liga Árabe de Estados em tentar promover a cooperação intra-árabe remontam ao ano de 1950, com a assinatura do Tratado da Junta de Defesa e Cooperação Econômica (em inglês, Treaty on Joint Defence and Economic Cooperation - TJDEC), que tinha como principal objetivo promover uma ação coordenada que garantisse o desenvolvimento econômico dos signatários. Esse foi o primeiro de uma série de cinco tratados que, nos últimos cinqüenta anos, visaram dar impulso à integração político-econômica intra-árabe.

Primeiro fruto do TJDEC, em 1953 é assinado o Tratado sobre Trânsito Comercial (TTC), que objetivava facilitar as trocas comerciais entre os Estados árabes por meio do estabelecimento de tarifas preferenciais para alguns produtos agrícolas e minérios.

Ainda dentro do escopo do TJDEC, foi lançado, em 1964, o ambicioso Mercado Comum Árabe (MCA), cujo objetivo era garantir a livre circulação de mercadorias, mão-de-obra e capital em um prazo de cinco anos. Assim como o TTC de 1953, o MCA não avançou e sua proposta foi abandonada poucos anos depois.

Já o Acordo para a Facilitação e Promoção do Comércio Intra-Árabe (em inglês, Agreement for the Facilitation and Promotion of TradeAfpat), de 1981, era bem menos ambicioso do que o MCA, pois tinha como objetivo a liberalização progressiva de tarifas com cuidadosas listas de exceções e prazos flexíveis para a implantação das medidas necessárias à constituição de uma área de livre-comércio intra-árabe. Porém, uma vez mais, os esforços da Liga Árabe foram em vão e o projeto do Afpat foi abandonado ainda em seu estágio inicial. 
A Área Árabe Ampliada de Livre Comércio (em inglês, Greater Arab Free Trade Area - GAFTA) representa o atual esforço da Liga Árabe em promover a integração econômica na região do Oriente Médio e Norte da África (OMNA). ${ }^{2}$ Lançada na reunião de cúpula da Liga em 1996, a GAFTA retoma o projeto abandonado do Afpat de 1981 e inova-o, na medida em que o setor privado, representado pela União das Câmaras de Comércio Árabe, foi convidado a monitorar todo o processo de implantação dessa área de livre-comércio. Até o presente momento, contudo, poucos indícios apontam para o comprometimento dos Estados signatários da GAFTA em implementar as medidas estipuladas pelo seu tratado de criação, que data de janeiro de 1998.

No plano sub-regional e, portanto, fora dos auspícios da Liga Árabe, mas ainda motivados pelo pan-arabismo, também se encontram exemplos de tentativas de integração político-econômica, como a República Árabe Unida (RAU, de 1958), a Federação das Repúblicas Árabes (1971), o Conselho de Cooperação do Golfo (CCG, de 1981), a União do Magreb Árabe (UMA, de 1989) e o Conselho de Cooperação Árabe (CCA, de 1989). Destes, apenas o CCG e a UMA permanecem em atividade, ainda que com sérios problemas estruturais.

Por fim, dois casos de unificação política e territorial no Mundo Árabe podem ser destacados: a formação dos Emirados Árabes Unidos, em 1971, e a reunificação do Iêmen do Norte e do Sul, em 25 de maio de 1990.

Esse breve resumo de cinco décadas de tentativas, tanto políticas quanto econômicas, de integração intra-árabe nos níveis regionais e sub-regionais indica a relevância e a complexidade do problema representado pelo regionalismo árabe, tema deste artigo, que expõe os resultados obtidos durante a pesquisa que resultou na dissertação de Mestrado intitulada "A (des)construção da Grande Nação Árabe: 
condicionantes sistêmicos, regionais e estatais para a ausência de integração política no Mundo Árabe". Nessa dissertação, foram investigados os diversos aspectos envolvidos no aparente contra-senso representado pela realidade política da região (desintegrada) em comparação com o discurso nacionalista árabe (integrador).

Para se ter uma idéia clara do nacionalismo árabe, ou pan-arabismo, é preciso entendê-lo em termos políticos - um movimento com diferentes ideologias, lideranças e partidos - e institucionais - com a proeminência da Liga Árabe de Estados e dos encontros periódicos de cúpula dos chefes de Estado árabes.

Em termos políticos, o nacionalismo árabe nasceu nos clubes literários de Damasco, no final do século XIX, e começou a florescer e a se desdobrar em diversos movimentos nos anos que precederam a Primeira Guerra Mundial. Esses movimentos bradavam por um "despertar árabe"3 - a emergência de uma identidade árabe.

Durante essa fase inicial do pan-arabismo, tentou-se promover e definir o próprio conceito de Nação Árabe, criar um vocabulário político para o nacionalismo árabe e identificar o "nós" e o "eles" na geografia da identidade (BARNETT, 1993).

"Nós", neste caso, referia-se à comunidade imaginada formada por aqueles que "falavam árabe, olhavam para a história dos árabes com orgulho e consideravam-se árabes” (KHALIDI, 1991, p. 1.365). "Eles", logicamente, referia-se a todos aqueles que não compartilhavam do sentimento de "companheirismo profundo e horizontal"4 com aqueles que pertenciam à Nação Árabe.

O próprio conceito de Mundo Árabe nasceu durante essa fase inicial e o termo está intimamente conectado com a idéia de "nós" definida acima. 
De acordo com Barnett (1993, p. 281), entre a Primeira e a Segunda Guerra Mundial, o nacionalismo árabe fortaleceu-se em virtude de cinco fatores principais: 1) a norma da autodeterminação, que legitimou e reforçou o desejo dos nacionais árabes por independência; 2) as promessas e garantias de autonomia feitas tanto pelo Império Otomano quanto pelas forças aliadas, durante a Primeira Guerra; 3) o estabelecimento do Sistema de Mandatos e a divisão dos territórios árabes sob controle britânico e francês, desconsiderando tanto as divisões geográficas e históricas da região quanto as lideranças locais; 4) o sentimento de traição despertado pelas potências ocidentais nas populações árabes, fruto do reconhecimento do Império Britânico da legitimidade do movimento sionista; e 5) o desenvolvimento dos sistemas de comunicação.

É creditada ao principal teórico do Ba'th, Michel 'Aflaq, a definição do conceito e dos termos que viriam a definir o que seria o pan-arabismo: "Só há uma nação árabe, com direito a viver num único Estado unido" (HOURANI, 1994, p. 406).

Embora já tivesse o seu significado político definido nas palavras de Michel 'Aflaq, o nacionalismo árabe era interpretado de maneiras diferentes pelos líderes árabes. Embora se identificassem como panarabistas e defendessem a unidade regional, eles discordavam dos projetos políticos associados com esse nacionalismo. Para alguns, o estreitamento dos laços econômicos, culturais e de segurança, com respeito à soberania estatal, era o bastante. Para outros, no entanto, as fronteiras territoriais estipuladas pelas potências coloniais deveriam ser apagadas, emergindo assim um Estado Árabe Unido, correspondente à Nação Árabe. Esse debate repercutiria nas conversações que precederam a criação da Liga Árabe de Estados.

Durante a Conferência de Alexandria, realizada em setembro de $1944,{ }^{5}$ o principal problema discutido foi o de como deveria ser a estrutura organizacional da Liga Árabe a ser criada. Seria ela um Esta- 
do unitário, com uma autoridade política central? Ou seria a Liga um Estado federado com um parlamento central e um comitê executivo com total poder político sobre as questões federais? Ou, ainda, uma confederação frouxa, com ênfase na coordenação e na cooperação, seria criada? De comum acordo, e com o apoio explícito da Grã-Bretanha, a última opção foi escolhida.

Como foi dito anteriormente, embora houvesse variações no significado dos projetos políticos regionais que deveriam ser associados ao nacionalismo árabe - desde a completa unificação política e territorial dos Estados até uma cooperação intra-árabe com a permanência das fronteiras estabelecidas pelas forças coloniais -, a constituição da Liga Árabe era vista como um primeiro passo rumo à realização de um futuro Estado Árabe Unido (KHADDURI, 1946).

Se esta era a intenção dos membros fundadores da Liga, ela não ficou clara na Carta do Pacto da Liga Árabe. No artigo 2 da Carta, é enfatizado que uma das atribuições da Liga seria a de "salvaguardar a independência e soberania [dos Estados árabes]” (LEAGUE OF ARAB STATES, 1945, p. 267). Ao enfatizar a proteção da soberania e independência dos países em vez da unificação política, a recém-criada Liga demonstrava que a unidade árabe não era uma questão de prática política, mas de "sentimento".

Claro parece estar que existia, naquele início da formação do Sistema Árabe de Estados, uma distância entre o ideal de unidade pan-árabe e a realidade política regional, e a maneira como a Liga foi constituída era um reflexo dessa dicotomia.

Na verdade, mesmo que a Liga Árabe tenha sido criada para preservar a independência dos Estados árabes - tanto em relação às grandes potências quanto deles mesmos (!) -, ela assumiu o papel de instituição do pan-arabismo, o principal elo entre os seus Estados-membros, por meio do qual os líderes árabes podem discutir os limites e as pos- 
sibilidades de seu nacionalismo comunal, promovendo, assim, o estreitamento dos laços entre os Estados do OMNA.

Se, nas primeiras fases do nacionalismo árabe, buscava-se identificar quem fazia parte da comunidade "nós árabes", a criação da Liga e seu desenvolvimento em uma instituição com 22 membros não deixam mais dúvida quanto ao que vem a ser, ou não, um Estado árabe. Como consta no artigo 1o da Carta: "Todo o Estado árabe independente tem o direito de tornar-se membro da Liga, se ele assim desejar" (LEAGUE OF ARAB STATES, 1945, p. 266). Sendo assim, os 22 Estados-membros da Liga ${ }^{6}$ constituem o Mundo Árabe, já referido aqui diversas vezes.

E, se esse "mundo" não se vê como uma parte isolada do sistema internacional, certamente se percebe como um subsistema, o qual se denomina, a partir da proposição de Korany (1999, p. 37-38), "Sistema Árabe de Estados".

Este sistema vê o Mundo Árabe como uma nação, que tem interesses comuns e prioridades de segurança distintas daquelas dos países capitalistas centrais. De acordo com a lógica do Sistema Árabe de Estados, os países do Oriente Médio e Norte da África que gozam de unidade lingüística, religião, história e cultura poderiam criar e desenvolver seu próprio sistema - econômico, político e estratégico - para contrapor as ameaças que surgissem de fora desse sistema.

Em vista do apresentado acima, inevitavelmente surge um questionamento: o que condiciona o Mundo Árabe a viver uma permanente fragmentação, a despeito de todo o discurso unificador do panarabismo?

O caminho para o encontro de uma resposta satisfatória é apontado por Hudson (1999, p. 15):

“[...] os obstáculos para a unidade [árabe] situam-se em quatro categorias: fatores sociopolíticos internos; interesses econômicos que não se susten- 
tam; a estrutura dos sistemas árabe/não árabe de Estado; e os padrões estratégicos, econômicos e culturais exógenos [ao Sistema Árabe de Estados]”.

Essas categorias de obstáculos à integração no Mundo Árabe apontadas por Hudson (1999) remetem diretamente aos pressupostos teóricos do realismo estrutural na versão da chamada Escola Inglesa, tendo em vista que esse trabalha com a idéia de que os fenômenos internacionais - entre eles, a cooperação entre os Estados - devem ser analisados em três níveis distintos: o estrutural, o da interação e o das unidades.

O realismo estrutural, concebido a partir das idéias de alguns dos teóricos da Escola Inglesa, tais como Buzan, Little e Jones (1993), é apresentado, no livro A lógica da anarquia, como uma espécie de síntese superior das abordagens liberais e realistas, compatível com o marxismo e capaz de transformar uma teoria da política internacional em uma teoria das relações internacionais.

Na versão proposta por Buzan, Little e Jones (1993), o realismo estrutural é capaz de oferecer uma síntese superior das abordagens liberais e realistas e ser compatível com o marxismo, porque, embora se assuma como uma extensão da tradição realista, também se abre para as abordagens de interdependência do liberalismo e, assim como os marxistas, vê a fundamentação histórica e empírica como condição necessária para o entendimento das relações internacionais.

Conforme dito anteriormente, no realismo estrutural, três níveis distintos de análise devem ser considerados no estudo do setor político internacional: o estrutural, o da interação e o das unidades.

O nível de análise estrutural está dividido em estrutura profunda, na qual o princípio organizacional é a anarquia e a inexistência de diferenciação de função entre as unidades, ou seja, todos os Estados são soberanos e exercem mais ou menos as mesmas funções; e estrutura distribucional, com os padrões sistêmicos na distribuição dos atribu- 
tos das unidades, analisável a partir dos conceitos de polaridade e estratificação.

No nível de análise da interação, encontra-se a capacidade de interação sistêmica, que pode ser estudada a partir dos conceitos de qualidade absoluta das capacidades tecnológicas (transportes, comunicação, informação) e de qualidade absoluta das capacidades sociais (regimes, normas e instituições), ambas por intermédio do sistema.

Por fim, tem-se um terceiro nível de análise, o da unidade, dividido em formações processuais - analisável a partir das relações de ação-reação entre os Estados e padrões recorrentes de ação-reação (alianças, equilíbrio de poder, corrida armamentista) - e análise de atributo, que pode ser apreciado a partir do estudo do comportamento dos Estados em termos de atributos de poder (política externa, protecionismo, papéis).

Este artigo busca apresentar os resultados obtidos na pesquisa que deu origem à dissertação supra-referida, que se propôs a entender os fatores que obstaculizam a integração política e econômica no Mundo Árabe. O foco será direcionado para as seguintes variáveis analíticas propostas pelo realismo estrutural: estrutura distribucional (nível de análise sistêmico); qualidade absoluta das capacidades sociais (nível de análise da capacidade de interação); e formações processuais (nível de análise das unidades).

Essa escolha permitiu uma investigação mais sistemática das categorias de obstáculos à integração política no Mundo Árabe apontadas por Hudson (1999), as quais já foram referidas anteriormente.

$\mathrm{Na}$ análise da estrutura distribucional, observaram-se as polaridades existentes no sistema internacional (uni-bi-multi-polaridade) e seus efeitos sobre a ausência de integração política no Mundo Árabe. Os critérios que permitiram classificar o tipo de polaridade existente foram fornecidos por Waltz (1979, p. 57): "Historicamente, apesar das 


\section{Silvia Ferabolli}

dificuldades, encontra-se acordo geral sobre quais são os grandes poderes de um dado período".

Ainda dentro da estrutura distribucional, mas no que concerne à estratificação, foi trabalhada a idéia de dependência econômica externa no Mundo Árabe e seus efeitos "obstaculizadores" para uma integração política na região do OMNA. Dependência aqui entendida como uma situação na qual uma economia é condicionada pelo desenvolvimento e expansão de outra economia (THEOTONIO DOS SANTOS apud ALNASRAWI, 1991).

Quanto à capacidade de interação, essa será avaliada apenas por meio da observação da qualidade absoluta das capacidades sociais, ou seja, pelo grau de institucionalização do Sistema Árabe de Estados. Esse sistema, de acordo com Barnett (1993, 1995, 1998), é composto por duas instituições ${ }^{7}$ que se sobrepõem - o pan-arabismo e a soberania estatal. Essas atribuem papéis diferentes a cada um dos membros da Liga Árabe, pois enquanto a soberania proíbe a interferência nos assuntos domésticos dos Estados árabes, o pan-arabismo não só sanciona isso como também nega a distinção entre o doméstico e o internacional dentro do Sistema Árabe de Estados. Assim, a tensão existente entre as instituições nacionalismo árabe e soberania estatal, bem como a falta de capacidade da Liga Árabe para lidar com essa questão, fornece os critérios para avaliação de como os baixos níveis de institucionalização do Sistema Árabe de Estados afetam a possibilidade de uma integração política no Mundo Árabe.

No que concerne às formações processuais no nível de análise das unidades, foram observadas as diferentes formas de equilíbrio de poder intra-árabe. De acordo com Silva e Gonçalves (2005), em termos de política externa, a prática do equilíbrio de poder ocorre quando um Estado procura evitar que outro ou outros Estados alcancem a posição de predomínio, ameaçando de algum modo seus interesses ou até mesmo sua soberania. Assim, os Estados formam alianças ou fa- 
zem política para contrabalançar a aquisição de poder por outro, ou outros Estados.

Segundo Korany (1999), o Mundo Árabe já passou por experiências variadas de equilíbrio de poder, desde pretensões hegemônicas por parte de um ator até a difusão de poder que impera na região desde a década de 1970. Suas observações forneceram-nos os critérios para avaliar o peso relativo do equilíbrio de poder dentro do Sistema Árabe de Estados para a ausência de integração política e econômica no Mundo Árabe.

Por fim, no que diz respeito, uma vez mais, aos padrões recorrentes de ação-reação entre os Estados árabes, buscou-se observar de que maneira a falta de complementaridade econômica na região do OMNA obstaculiza a integração política na região.

Este artigo tem como pressuposto a afirmação de que não existe integração política no Mundo Árabe - mesmo que se considere que as relações entre as unidades que formam o Sistema Árabe de Estados não se caracterizam pela completa desunião.

Essa afirmação passa pelo entendimento de integração política enquanto sinônimo de "coesão regional", conceito proposto por Hurrel (1995), outro autor ligado à Escola Inglesa. Segundo ele, a coesão regional refere-se à possibilidade de, em algum momento, processos de regionalização, consciência e identidade regionais, cooperação regional entre Estados e integração econômica regional promovida pelo Estado combinarem-se e desembocarem no surgimento de uma unidade regional coesa e consolidada.

Coesão regional, ainda de acordo com Hurrel (1995), deve ser entendida aqui em dois sentidos: quando a região exerce um papel definidor nas relações entre os Estados e outros atores importantes daquela região e o resto do mundo; e quando forma a base organizadora de 
políticas na região para inúmeras questões. O exemplo mais conhecido de unidade regional coesa é a União Européia.

Os termos "integração política" e "coesão regional" são usados, neste trabalho, como sinônimos, da mesma maneira que o será o conceito de "regionalismo". Isso porque, como observa John Friedman, “[...] as comunidades políticas surgem a partir de uma escolha política" (apud GORE, 1984, p. 227), ou seja, "[as regiões] são subjetivamente definidas pelos homens [...] criadas por alguém, com algum propósito" (GORE, 1984, p. 230-231).

Importante seria ressaltar que o próprio conceito de coesão regional parte da junção de quatro categorias analiticamente diversas de regionalismo. A primeira diz respeito à regionalização, em que processos econômicos autônomos levam a interdependência econômica em determinadas áreas a níveis mais elevados do que a interdependência entre estas áreas e o resto do mundo. A segunda seria a consciência e a identidade regionais, que se referem a uma percepção compartilhada de pertencer a uma determinada comunidade. Já a cooperação regional entre Estados se refere à negociação e construção de acordos ou regimes interestatais e intergovernamentais. Quanto à integração econômica regional promovida pelo Estado, essa está diretamente relacionada com as decisões específicas de políticas por parte dos governos destinadas a reduzir ou remover barreiras ao intercâmbio mútuo de bens, serviços, capital e pessoas. No momento em que esses quatro processos descritos estiverem consolidados, sua combinação pode dar origem ao surgimento, como dito anteriormente, de uma unidade regional sólida e coerente (HURREL, 1995).

Dada a devida atenção às diversas categorias analíticas do regionalismo e ao próprio conceito final de coesão regional, fica claro que não existe integração política no Mundo Árabe. Todavia, enquanto esta constatação é facilmente observável e relativamente consensual entre os especialistas, a explicação sobre as causas desse fenômeno per- 
manece incompleta e polêmica. Daí a relevância da pesquisa que deu origem a este artigo, que se propôs a explicar, dentro do escopo de uma teoria das Relações Internacionais, porque a integração intra-árabe fracassou nos últimos cinqüenta anos.

Mesmo considerando que "a rua" árabe manifesta o entusiasmo de pertencer a uma comunidade maior - "nós árabes" -, não se pode negar que os processos de regionalização e integração econômica regional intra-árabe ainda estão em estágios iniciais de desenvolvimento, vide as diversas tentativas de integração econômica promovidas pela Liga Árabe que nunca se concretizaram. Quanto à cooperação regional entre os Estados árabes, essa parece sempre esbarrar na falta de vontade política das lideranças árabes, no que suas motivações para tal comportamento também foram parte constituinte da pesquisa.

Cabe ainda ressaltar que se trabalha com o conceito de integração política e não econômica porque se entende que uma vez que seja tomada uma decisão política rumo à cooperação, essa pode levar à integração econômica (GILPIN, 2001). Assume-se, então, que uma integração política intra-árabe teria levado a região a alcançar a propagada integração econômica pan-árabe.

Para que fosse possível discutir a problemática associada à ausência de integração política no Mundo Árabe, optou-se por delimitar o período histórico a ser analisado entre os anos de 1954 e 2004. O ponto de partida é representado pela ascensão de Nasser ao poder no Egito, dando início à era denominada por Hourani (1994) de "auge do arabismo". O ano que delimita o fim da pesquisa é 2004, porque se buscou observar as repercussões da invasão do Iraque pelos Estados Unidos, em 2003, sobre o Sistema Árabe de Estados.

Esse período maior, de cinqüenta anos (1954-2004), foi ainda dividido em três períodos menores, a saber, 1954-1973, 1973-1990 e 1990-2004. Isso porque se entendeu que o choque petrolífero de 1973 marcou uma nova era das relações internacionais árabes, assim 
como a Guerra do Golfo, em 1990, também representou uma era de ruptura no padrão de relações entre os Estados árabes.

Em cada um desses períodos, foi analisado o peso relativo dos condicionantes sistêmicos, regionais e estatais para a ausência de integração política-econômica intra-árabe, conforme proposto pela metodologia de análise dos fenômenos internacionais apresentada pelo realismo estrutural sob a "versão" da Escola Inglesa, e apenas dentro do escopo selecionado para essa pesquisa, a ratificar: condicionante sistêmico (estrutura distribucional $)=$ polaridade no sistema internacional; condicionante sistêmico (estrutura distribucional/estratificação) = dependência econômica externa do Mundo Árabe; condicionante subsistêmico/regional (capacidade de interação/qualidade absoluta das capacidades sociais) = institucionalização do Sistema Árabe de Estados; condicionante estatal (formações processuais) = equilíbrio de poder no Mundo Árabe; condicionante estatal (padrões recorrentes de ação-reação) $=$ complementaridade econômica entre os Estados árabes.

Os resultados obtidos são os seguintes:

1) Entre os anos de 1954 e 1973, temos um Mundo Árabe recém-independente politicamente, mas não economicamente, que sofre os efeitos da Guerra Fria e que é atormentado pela difícil escolha entre soberania estatal e pan-arabismo. Essa situação é intensificada pela hegemonia egípcia e pela tentativa das monarquias do Golfo de controlar a região de acordo com seus interesses.

Durante esse primeiro período, o peso relativo que as duas superpotências tiveram para a ausência de integração no OMNA foi limitado.

Os Estados Unidos tentaram organizar um Mundo Árabe dividido contra a União Soviética, via Pacto de Bagdá (1955), mas fracassaram em decorrência, especialmente, da pressão que Nasser exerceu sobre os Estados árabes contra o referido pacto. A ousadia do Iraque 
de ingressar em uma aliança ocidental em pleno auge do arabismo, que pregava a independência dos Estados árabes em relação aos "ditames do Ocidente", teve como consequiência o isolamento do país na política regional e a derrubada de seu regime, em 1958.

Ainda, a doutrina Eisenhower (1957), empregada no Líbano e na Jordânia, sob o pretexto de barrar ameaças comunistas, mas com o objetivo último de conter Nasser, acabou por restringir-se a essas duas intervenções, e não foi a responsável imediata pelo enfraquecimento do poderio do regime nasserista.

Quanto à União Soviética, sua inserção no Mundo Árabe era limitada pelo anticomunismo típico da região. Suas ações eram restritas à venda de armamentos e ao apoio diplomático contra Israel. Os soviéticos não se dispuseram a patrocinar a integração no OMNA sob a égide egípcia, o que poderia ser feito via apoio à política expansionista de Nasser, por duas razões fundamentais: falta de poder econômico para tanto e temor de que um superEstado árabe-islâmico às margens de suas fronteiras pudesse ser criado, o que geraria, inevitavelmente, tensões em suas repúblicas islâmicas.

Para os soviéticos, assim como para os norte-americanos, a existência de um "Mundo Árabe" era irrelevante, já que a região que os interessava era o Oriente Médio, que compreendia alguns Estados árabes, mas também englobava a Turquia, o Irã e Israel. Por certo que a região do OMNA compreende também os citados países, mas não dentro do conceito de Sistema Árabe de Estados. Assim, ao tentar angariar aliados dentro do Sistema Oriente Médio, desrespeitando a geografia que une os povos árabes, Estados Unidos e União Soviética reforçavam as tensões já existentes dentro do próprio Sistema Árabe de Estados. Essa tendência se acentuaria no pós-Yom Kippur e atingiria seu ápice com os desdobramentos da Guerra do Golfo.

A explosão do nacionalismo árabe, no pós-1956 (crise de Suez), incentivou os Estados árabes produtores de petróleo a rever os termos 
absolutamente desfavoráveis de concessões presentes nos contratos com as multinacionais petrolíferas. Esse movimento levou à criação da Organização dos Países Exportadores de Petróleo (OPEP), em 1960, da Organização dos Países Árabes Exportadores de Petróleo (OPAEP), em 1968, e à conclusão do Acordo de Teerã (1971), iniciativas que alteraram drasticamente o padrão de relações entre as companhias petrolíferas e os governos produtores da commodity.

A dependência econômica externa do Mundo Árabe foi, e continua sendo, um dos principais empecilhos para a integração da região. As décadas de subordinação aos interesses europeus, fruto do colonialismo que imperou no OMNA por quase meio século, fez com que as economias árabes se atrelassem àquelas européias, o que acabou por criar padrões de relações econômicas não entre os Estados árabes, mas entre cada um deles isoladamente e a Europa.

Se o nacionalismo petrolífero foi responsável por matizar a expropriação das riquezas árabes pelas multinacionais do petróleo, ele não conseguiu romper com os padrões de alinhamento às demandas da economia internacional por parte de alguns Estados árabes muito importantes, notadamente a Arábia Saudita. Se, no período compreendido pelos anos de 1954 a 1973, a opção saudita pelo alinhamento com os países capitalistas centrais, especialmente com os Estados Unidos, não teve grandes repercussões sobre o Mundo Árabe, será visto que a explosão dos preços do petróleo, na década de 1970, lhe proporcionará os recursos financeiros necessários para impor a sua visão de cooperação intra-árabe, a qual não supõe, de forma alguma, integração política.

As fontes de poder bruto e brando egípcios alçaram o país de Nasser à condição de hegêmona do Mundo Árabe. O modo como ele buscou a integração do OMNA, via campanhas agressivas de propaganda, subversão e ações militares, foi responsável por um grande período de instabilidade regional, já que sua política era percebida pelos líde- 
res árabes como expansionista e eles temiam que uma integração política na região, naquele período de hegemonia egípcia, certamente se daria sob o comando de Nasser.

Mas o regime nasserista precisava de recursos financeiros para pôr em prática seu projeto de construção da unidade árabe sob o comando egípcio, e aqueles que detinham poder econômico na região, as petromonarquias, não estavam dispostos a investir suas riquezas em uma aventura integracionista na qual sabiam que perderiam em termos de poder político e prestígio, tal qual aconteceu com a Síria nos anos da RAU (1958-1961).

Os anos de liderança egípcia no Sistema Árabe de Estados findaram com a Guerra dos Seis Dias, em 1967, porque, na reunião da Liga Árabe realizada em Cartum, no mesmo ano, para decidir o futuro dos Estados árabes depois da derrota contra Israel, Nasser foi obrigado a desistir, em troca de apoio financeiro, de sua política de espalhar os ideais de unificação pan-árabe pela região.

Na medida em que a hegemonia egípcia teve um peso relativo maior para a ausência de integração política no Mundo Árabe nos anos de 1954 a 1973, de forma geral, e de 1956 a 1967, de forma mais específica, deve ser entendida dentro do contexto das tensões entre soberania estatal e pan-arabismo, vigentes na região desde a formação do Sistema Árabe de Estados, ainda na década de 1940.

Essas tensões diziam respeito ao direito à existência dos Estados árabes. Ora, se o lema básico do pan-arabismo é o de que "só há uma Nação Árabe, com direito a viver em um único Estado unido", então os governantes que defendiam a união intra-árabe estavam, na verdade, reconhecendo a própria natureza transitória de seus Estados. Trabalhar em favor da unificação árabe era aceitar que, mais cedo ou mais tarde, as fronteiras estabelecidas pelas potências européias seriam apagadas e que a Nação Árabe emergiria, soberana - sob o comando de Nasser! 
Como reconhece Barnett (1998, p. 31) “[...] tendo trabalhado arduamente por sua independência, os governos árabes estavam pouco empolgados em desistir de sua recém-adquirida soberania em nome de uma entidade maior na qual eles teriam seu poder político reduzido". O próprio fracasso do Mercado Comum Árabe esteve inserido na contradição existente entre promover a integração econômica e frear a integração política.

Dessa forma, ratifica-se que, no período compreendido entre os anos 1954 e 1973, a associação dos condicionantes de ordem estatal (nível de análise da unidade), representados pelo equilíbrio de poder intra-árabe, com os fatores de ordem regional (nível de análise do subsistema/regional), representados pela capacidade de interação sistêmica árabe, teve um peso relativo maior para a ausência de integração política no Mundo Árabe.

A partir do consenso de Cartum, os Estados árabes entraram em uma nova fase de suas relações: os termos "integração" e "unificação" deixaram de ser sinônimos e ainda cederam lugar para o conceito de "cooperação".

2) Entre os anos de 1973 e 1990, deu-se a vitória estadunidense sobre a URSS no Mundo Árabe, fruto, especificamente, dos desdobramentos de Yom Kippur. Esse período testemunhará o aprofundamento da dependência externa árabe, a primazia dos petropoderes e a conseqüente difusão de poder, expressa na opção pelos acordos econômicos sub-regionais, a mencionar, CCG, UMA e CCA.

A deflagração da Guerra de Yom Kippur (1973) foi resultado direto da humilhante derrota imposta por Israel aos países árabes, em 1967, e esses últimos poderiam ter, efetivamente, vencido o exército israelense não fosse a massiva ajuda que esse recebeu dos norte-americanos. Essa firme disposição dos Estados Unidos para defender seu maior aliado no Oriente Médio enfureceu as lideranças árabes, que usaram o petróleo como arma política, expresso no plano 
de embargo de outubro de 1973. Contudo, esse foi totalmente levantado em março de 1974, sem que suas demandas tivessem sido atendidas, quais fossem: a devolução dos territórios ocupados por Israel na Guerra dos Seis Dias e a restauração dos direitos palestinos. Além disso, o choque petrolífero de 1973-1974 não foi resultado direto do embargo, mas da manipulação da crise por parte da OPEP com o objetivo de aumentar o preço do barril de petróleo no mercado internacional.

A Guerra Fria foi formalmente encerrada no Mundo Árabe, já no início da década de 1970, em virtude do sucesso da diplomacia Kissinger - que resultou nos acordos de paz entre Egito e Israel - e da opção egípcia pelo financiamento norte-americano de seu projeto de reestruturação política e econômica. As relações entre Arábia Saudita e Estados Unidos aprofundaram-se no pós-Yom Kippur, mas a paz em separado entre Egito e Israel fez desse primeiro o principal aliado árabe dos norte-americanos, posto outrora ocupado pelos sauditas. Essa situação não impediu que a Arábia Saudita mantivesse sua aliança com os Estados Unidos, mas obrigou-a a romper relações com o Egito, em decorrência, especialmente, da pressão exercida pela Revolução Iraniana (1979) para que os povos islâmicos impedissem que seus líderes se aliassem a governos pró-norte-americanos. A entrada definitiva dos Estados Unidos na região do OMNA deu-se por meio de dois Estados que negavam a unidade árabe - o Egito de Sadat e a Arábia Saudita.

O peso relativo dos condicionantes sistêmicos, representados pelo tipo de polaridade existente no sistema internacional, sobre a ausência de integração no OMNA, entre 1973 e 1990, foi ampliado em relação ao período anterior. Isso porque, até 1970, ano da morte de Nasser, o Egito manteve-se como guardião da porta de entrada para o Mundo Árabe, impedindo a penetração dos Estados Unidos na região. A ambição de Sadat de construir um Egito moderno, a qualquer custo, o impeliu a vender a chave das portas egípcias para aqueles que 
tinham poder para comprá-la: a Arábia Saudita no plano subsistêmico árabe e os Estados Unidos no plano sistêmico internacional. Essa metáfora revela que, na verdade, o peso relativo desses condicionantes sistêmicos como uma força que impediu a integração no Mundo Árabe, no período de 1973 a 1990, foi determinado não apenas pelo poderio norte-americano, mas, especialmente, por questões de ordem doméstica árabe. Ou seja, os Estados Unidos não precisaram arrombar as portas da região; eles foram convidados a entrar por uma Arábia Saudita desejosa de proteção político-militar e por um Egito sedento de financiamento econômico.

O aprofundamento da dependência econômica externa no Mundo Árabe deu-se no pós-choque petrolífero, por meio do fenômeno da dependência secundária, na qual os Estados árabes não produtores de petróleo ficaram dependentes da remessa de seus trabalhadores migrantes e da ajuda financeira dos países árabes membros da OPEP, que, por seu turno, dependiam, e dependem, dos valores do petróleo no mercado internacional.

A dependência externa árabe foi, é e sempre será um condicionante sistêmico importantíssimo para a ausência de integração no OMNA, na medida em que uma região dependente economicamente perde margem de manobra no processo de tomada de decisão política. Contudo, o aprofundamento da dependência econômica árabe também foi resultado de opções domésticas, já que as monarquias do Golfo, especificamente, poderiam ter investido uma grande parte de seus superávits econômicos no desenvolvimento da região, mas optaram por não fazê-lo. Da mesma forma, os Estados árabes exportadores, não de petróleo, mas de mão-de-obra farta e barata, perderam a oportunidade de financiar projetos internos de desenvolvimento agrícola e industrial, com a remessa de seus trabalhadores migrantes e com a ajuda das agências especializadas árabes. O "ouro negro", que deveria ser uma benção para a região, revelou-se uma doença 
que, ao final da década de 1980, havia corroído praticamente todas as economias árabes, aumentando ainda mais a dependência da região.

No que concerne ao equilíbrio de poder intra-árabe, observou-se que a opção de Sadat pela paz em separado com Israel e pelo alinhamento com os Estados Unidos (Acordos de Camp David, 1978-1979) levou ao isolamento do Egito no Mundo Árabe, o que desencadeou um processo de fragmentação política regional, fruto do vácuo de poder deixado pelos egípcios e não ocupado pelas petromonarquias, o que acabou por produzir reclames de hegemonia por parte do Iraque, Síria e Líbia. Nessa situação de ausência de liderança regional, o OMNA presenciou uma série de conflitos intra-árabes (guerra civil libanesa e Saara Ocidental) e a respectiva formação de eixos e alianças, ambos se apresentando como causa e conseqüência do processo de fragmentação política árabe pós-1973.

Esse processo foi resultado direto da política "o Egito primeiro", de Sadat, que resultou na capitulação egípcia diante do poderio econômico norte-americano, expresso na assinatura dos Acordos de Camp David. A conseqüência da opção unilateral de Sadat foi a expulsão do país da ordem política e econômica regional, situação essa que Mubarak levou anos para reverter, e que só foi possível em virtude dos desafios impostos pela Revolução Iraniana e pela crescente reivindicação do Iraque ao posto de hegêmona do Mundo Árabe.

Enquanto o "coração e alma" da Nação Árabe - o Egito - batia em compasso com os Estados Unidos, as petromonarquias aproveitavam para estabelecer a sua própria ordem regional, calcada na diplomacia "talão de cheques", por meio da qual boas relações e estabilidade eram compradas com petrodólares. Essa política não alcançou muito êxito, já que "ordem" é uma palavra que, definitivamente, não descreve a situação política do OMNA pós-Camp David.

Dessa forma, entende-se que, durante os anos de primazia dos petropoderes (1973-1990), o Mundo Árabe ficou à deriva, sem uma lide- 
rança regional que oferecesse uma base alternativa para a integração pan-árabe proposta por Nasser. Nesse sentido, uma vez mais, os condicionantes estatais, representados pelo equilíbrio de poder intra-árabe, revelaram sua força para a ausência de integração no OMNA, na medida em que aquilo que se chama de status quo de orientação saudita nada mais é do que uma ordem regional que tem por base a defesa dos interesses dos regimes-família ricos em petróleo, que querem, buscam e promovem a cooperação vertical, com os Estados Unidos, e rejeitam, evitam e impedem a integração horizontal, intra-árabe.

Em meio a essa configuração política regional, que encontra nos termos fragmentação, difusão e desunião sua melhor definição, três agrupamentos sub-regionais árabes foram formados - CCG, UMA, CCA. O primeiro, nascido sob o signo do pavor perante a Revolução Iraniana e do desconforto de seus membros de terem que arcar com os custos do projeto integrativo econômico pan-árabe proposto pela Liga em 1980 (Estratégia Econômica Coordenada Árabe), uniu as petromonarquias do Golfo, separando a Nação Árabe dos lucros do petróleo. A UMA, que teve sua origem marcada pelo conflito no Saara Ocidental, encontra-se em situação de paralisia, exatamente em virtude da contenda saariana-marroquina-argelina. Sem um centro hegemônico capaz de atrair esses Estados para uma cooperação intra-árabe, eles vão lentamente encaminhando-se para a formação de acordos bilaterais com a Europa, afastando-se, cada vez mais, dos arranjos econômicos propostos pela Liga Árabe. Por fim, o CCA, cujo início e fim foi determinado, especialmente, pela nova posição que Saddam Hussein passou a desempenhar no Mundo Árabe: uma posição de contestação da ordem vigente e de reclamação de hegemonia. Esses três acordos "econômicos" sub-regionais reuniram, em conjunto, quinze dos 22 Estados da Liga Árabe, ou seja, praticamente $70 \%$ dos membros da Liga ficaram dispersos nesses agrupamentos, o que inviabilizou, no período compreendido entre os anos de 1973 e 
1990, uma integração econômica regional que incluísse todos os Estados árabes, conforme proposto pela Estratégia Econômica Coordenada Árabe, de 1980.

Em suma, os condicionantes sistêmicos, representados pelo tipo de polaridade existente no sistema internacional, e revelados pelo poderio que o Estado norte-americano alcançou na região no pós-Yom Kippur, tiveram um peso relativo maior para a ausência de integração no Mundo Árabe, entre os anos de 1973 e 1990. Porém, essa situação esteve diretamente relacionada com os condicionantes de ordem estatal, representados pela situação de equilíbrio de poder do OMNA nas décadas de 1970 e 1980, de capitulação egípcia e de primazia dos petropoderes. Ou seja, a associação das forças sistêmicas internacionais com os segmentos mais conservadores do Mundo Árabe foi determinante para a ausência de integração política intra-árabe nos anos compreendidos entre a Guerra de Yom Kippur e a Guerra do Golfo.

3) Entre os anos de 1990 e 2004, observou-se a tentativa de imposição do Sistema Oriente Médio na região do OMNA pelos Estados Unidos e as possibilidades de contraposição do Sistema Árabe de Estados diante da tentativa não só de domínio político norte-americano, mas também econômico europeu por meio dos Acordos Euromediterrâneos (EuroMed). A Guerra do Golfo abriu a discussão sobre o futuro dos países árabes produtores de petróleo na anunciada Nova Ordem Mundial e o tipo de equilíbrio de poder, ou de fraqueza, que impera no Mundo Árabe pós-Saddam Hussein.

O conceito de "Oriente Médio" é um termo imperialista por natureza, na medida em que a delimitação dessa região é definida pelos interesses dos grandes poderes. Dentro dessa perspectiva, a construção de um Sistema Oriente Médio, que nega a unicidade do Sistema Árabe de Estados, visa aglutinar os Estados árabes em torno de Israel e promover reformas econômicas, políticas e militares que sirvam aos 
interesses de norte-americanos e israelenses, a saber, luta contra o terrorismo, abertura econômica, segurança regional controlada pelos Estados Unidos e democratização - o "Novo Oriente Médio", de Shimon Perez.

A possibilidade de Saddam Hussein se assenhorear dos vastos recursos petrolíferos do Golfo Pérsico foi um dos principais determinantes da guerra de 1991. Assim, a excessiva dependência militar das petromonarquias em relação aos Estados Unidos limita, se não encerra, a possibilidade de uma cooperação política e de segurança intra-árabe. Isso porque qualquer projeto de integração árabe necessita, invariavelmente, do financiamento das petromonarquias. Porém, essas estão, cada vez mais, fechadas em si, por meio do Conselho de Cooperação do Golfo e, cada vez mais, dependentes da proteção norte-americana. Nessa situação, esses países retêm seus recursos econômicos, única e exclusivamente, para benefício próprio e investem no desenvolvimento não de uma segurança árabe, mas de uma petromonárquica. Contudo, a invasão norte-americana do Iraque, em 2003, mostrou que os Estados Unidos não estão mais dispostos a assegurar uma relação de cooperação com as petromonarquias, notadamente com a Arábia Saudita, mas impor um controle explícito sobre essas.

A destruição do Iraque como uma potência regional privou o Mundo Árabe de um país que tinha todas as condições para assumir a liderança do OMNA - não fosse pela veemência com que os Estados Unidos interromperam a construção de um Iraque-potência, os Estados árabes teriam que lidar com um regime iraquiano disposto a fazer aquilo a que Nasser se propôs, mas que nunca conseguiu alcançar: redesenhar o mapa político e econômico árabe e realizar, pela força, a utopia da Nação Árabe.

O grande problema associado a essa situação é que, desde o imediato pós-Guerra do Golfo, em virtude de nenhum Estado árabe possuir os 
requisitos necessários para assumir a liderança do Sistema Árabe de Estados, essa, então, passa a ser exercida por um ator externo de caráter global, no caso, os Estados Unidos. Dentro dessa perspectiva, falar de integração política no Mundo Árabe passa, necessariamente, pela aceitação de que essa se daria apenas sob o controle norte-americano, que quer, sim, uma integração na região, mas não sob a égide do arabismo, mas do Sistema Oriente Médio.

No que concerne ao grau de institucionalização do Sistema Árabe de Estados, entre os anos de 1990 e 2004, observou-se que a Declaração de Damasco (1991) ratificou os termos de Cartum de primazia da soberania como regulador das relações intra-árabes e ainda sancionou a não-obrigatoriedade da divisão das riquezas nacionais com a Nação Árabe. Ademais, no pós-Guerra do Golfo, a Liga Árabe enfraqueceu-se a tal ponto que seus 22 membros ficaram mais de cinco anos sem se reunir. Contudo, enquanto se especulava se o Sistema Árabe de Estados havia chegado ao fim com a invasão iraquiana do Kuwait em 1990, os membros da Liga reuniam-se em Sharm El-Sheikh em 2003 e declaravam ao mundo que uma agressão contra um Estado árabe seria considerada um ataque contra toda a Nação Árabe, em uma demonstração evidente de que o pan-arabismo, pelo menos no discurso, ainda é um forte marco regulador das relações intra-árabes. Não obstante, a insistência nos termos "soberania" e "exclusividade" revela, uma vez mais, que o ideal pan-árabe deve ficar no plano da retórica, e não da prática política.

A Liga Árabe de Estados tentou romper o ciclo de fragmentação econômica árabe propondo, em 1997, a formação de uma área de livre-comércio no OMNA, com o intuito de dar início a um grande projeto de integração econômica pan-árabe. A GAFTA tenta reviver o Acordo para Facilitação e Promoção do Comércio Intra-árabe, de 1981, mas tendo como novidade a participação da sociedade civil, já que o empresariado regional foi convidado a monitorar seu processo de implementação, que deverá ser concluído em 2008. O maior desa- 
fio que a GAFTA enfrenta, além daquele óbvio de convencer as lideranças árabes a fazerem movimentos mais concretos em direção à harmonização de suas políticas comerciais e econômicas, são os Acordos da Associação Euromediterrânea, que visam aglutinar os Estados árabes em torno de uma área de livre-comércio com a União Européia, que, caso venha a se concretizar, em 2010, conforme previsto, dificultará enormemente a realização dos objetivos da GAFTA. É comum economistas levantarem a tese de que não há complementaridade entre as economias árabes, ou que os níveis de comércio regional são muito baixos. Contudo, se o fator petróleo for desconsiderado, o comércio entre os países árabes, em comparação com o total mundial comercializado por esses, é de quase $20 \%$, o que revela, uma vez mais, que a ausência de integração econômica no Mundo Árabe não é determinada pela falta de complementaridade entre as economias árabes, ou por qualquer tipo de limitação de ordem comercial.

Ingerência externa é o termo que encarna o período histórico compreendido entre os anos de 1990 e 2004 no Mundo Árabe. Isso porque se entendeu que o poderio alcançado pelos Estados Unidos, no sistema internacional, com o fim da ordem bipolar, permitiu que esse país interferisse nas dinâmicas do Sistema Árabe de Estados em pelo menos três dos níveis de análise propostos na pesquisa: no próprio nível da polaridade existente no sistema internacional, no nível da dependência econômica externa árabe e no nível do equilíbrio de poder intra-árabe.

No que tange aos aspectos do tipo de polaridade existente no sistema internacional (nível de análise sistêmico) e seus efeitos sobre a integração intra-árabe, concluiu-se que a supremacia militar norte-americana sobre o Mundo Árabe, conquistada via estabelecimento de bases no Golfo Pérsico durante a Guerra do Golfo, a ocupação do Iraque em 2003 e a contínua assistência militar a seu principal aliado no Oriente Médio, Israel, têm permitido que os Estados Unidos 
determinem os rumos da política árabe, que devem se orientar não para uma integração intra-árabe, mas para os objetivos da política externa norte-americana no Oriente Médio, ou seja, a manutenção de Israel como a única potência regional e o controle do fluxo do petróleo árabe para o mercado internacional. A destruição do Iraque como uma potência árabe e o chamado processo de paz no Oriente Médio asseguram a posição israelense; já a dominação militar sobre as petromonarquias garante o controle sobre o petróleo árabe.

Também no que concerne aos aspectos envolvidos na dependência econômica externa árabe (nível de análise sistêmico), o papel dos Estados Unidos tem se mostrado determinante, na medida em que a já afirmada supremacia militar norte-americana na região assegura que o padrão de alinhamento típico das petromonarquias em relação às demandas do sistema econômico internacional deixe de ser uma questão de opção política e passe a ser uma questão de obrigação e subordinação. Dessa forma, mesmo que esses Estados se dispusessem a mudar a orientação de suas economias para uma volta ao financiamento de um projeto de integração intra-árabe, isso passaria, necessariamente, pelo aval norte-americano.

Por fim, no que concerne ao equilíbrio de poder intra-árabe (nível de análise da unidade/Estado), esse vem sendo, desde a Guerra do Golfo, mantido pela potência hegemônica do pós-Guerra Fria. Embora essa situação também favoreça, em alguma medida, as petromonarquias, que não precisam mais se preocupar com a emergência de uma nova potência árabe que desafie o status quo regional, é certo que nessa situação de equilíbrio de poder os interesses que se quer assegurar são exatamente aqueles norte-americanos, ou seja, a manutenção de Israel como a única potência regional e o controle do fluxo do petróleo árabe. Integração regional, nesses termos, supõe não só a participação de Israel como também a sua centralidade em um possível processo integrativo. 
Em suma, os condicionantes sistêmicos tiveram um peso relativo maior para a ausência de integração intra-árabe no período compreendido entre os anos de 1990 e 2004. Embora essa situação esteja diretamente relacionada com os condicionantes de ordem estatal, representados pela situação de equilíbrio de poder no OMNA, foi visto que esse equilíbrio passou a ser mantido exatamente pela potência hegemônica do pós-Guerra Fria. Dessa forma, as forças sistêmicas internacionais, representadas pela supremacia militar norte-americana no Mundo Árabe, foram determinantes para a ausência de integração política intra-árabe nos anos compreendidos entre a Guerra do Golfo e os momentos imediatamente posteriores à invasão norteamericana do Iraque.

\section{Conclusões}

A análise do peso relativo dos condicionantes sistêmicos, regionais e estatais para a ausência de integração política no Mundo Árabe, nos diferentes períodos selecionados para estudo, a constar, 1954-1973, 1973-1990 e 1990-2004, revelou o seguinte:

a) no período compreendido pelos anos de 1954 a 1973, a associação dos condicionantes de ordem estatal, representados pelo equilíbrio de poder intra-árabe, de hegemonia egípcia, com os condicionantes de ordem regional, representados pela capacidade de interação sistêmica árabe, e revelados pela forte tensão existente na época entre soberania estatal e pan-arabismo, teve um peso relativo maior para a ausência de integração política no Mundo Árabe;

b) no período compreendido entre os anos de 1973 e 1990, os condicionantes sistêmicos, representados pelo tipo de polaridade existente no sistema internacional, e revelados pelo poderio que o Estado norte-americano alcançou na região no pós-Yom Kippur, tiveram um peso relativo maior para a ausência de integração no Mundo Árabe. Porém, essa situação esteve diretamente relacionada com os condici- 
onantes de ordem estatal, representados pela situação de equilíbrio de poder do OMNA nas décadas de 1970 e 1980, de capitulação egípcia e de primazia dos petropoderes. Ou seja, a associação das forças sistêmicas internacionais com os segmentos mais conservadores do Mundo Árabe foi determinante para a ausência de integração política intra-árabe nos anos compreendidos entre a Guerra de Yom Kippur e a Guerra do Golfo; e

c) no período compreendido entre os anos de 1990 e 2004, os condicionantes sistêmicos tiveram um peso relativo maior para a ausência de integração intra-árabe e, embora essa situação estivesse diretamente relacionada com os condicionantes de ordem estatal, representados pela situação de equilíbrio de poder no OMNA, foi visto que esse equilíbrio passou a ser mantido exatamente pela potência hegemônica do pós-Guerra Fria. Dessa forma, as forças sistêmicas internacionais, representadas pela supremacia militar norte-americana no Mundo Árabe, foram determinantes para a ausência de integração política intra-árabe no período compreendido pelos anos de 1990-2004.

Tendo por base essas considerações, pode-se inferir que o processo não de construção, mas de desconstrução da chamada Grande Nação Árabe, que integraria política e economicamente os 22 Estados árabes, foi feito em três etapas. Em um primeiro momento, de 1954 a 1973, as petromonarquias financiaram o abandono de Nasser de sua política de espalhar os ideais de unificação pan-árabe pela região e promoveram a tese de que "integração" e "unificação" não eram sinônimos, e que tais conceitos deveriam ser substituídos pelo de "cooperação". Com o próprio significado de pan-arabismo enfraquecido em termos conceituais, chegou-se a um segundo momento, 1973-1990, quando os Estados Unidos têm as portas da região abertas por uma Arábia Saudita desejosa de proteção político-militar e por um Egito sedento de financiamento econômico - a primazia do doméstico em detrimento da integração regional é claramente revelada. Por fim, 
quando se chega no terceiro momento, 1990-2004, os Estados Unidos passam a dominar militarmente o Mundo Árabe, privando as lideranças locais inclusive de exercerem sua soberania estatal.

Em síntese, nos cinqüenta anos de história do nacionalismo árabe moderno, os líderes árabes não se orientaram para a construção de um projeto de integração político e econômico pan-árabe, mas, exatamente, para a sua não-realização. Nesse processo, eles foram se alinhando cada vez mais aos Estados Unidos, com o intuito de conseguir proteção política, militar e econômica para assegurar a sobrevivência de seus Estados artificialmente criados, sempre questionados pelo mesmo ideal pan-arabista que dá legitimidade aos seus regimes. Não obstante, a situação que se apresenta hoje é assegurar a sobrevivência dos regimes por meio do alinhamento compulsório aos Estados Unidos, o que, invariavelmente, choca-se com o ideal nacionalista árabe de libertação de toda a forma de ingerência externa. A problemática envolvida nessa situação vem gradualmente revelando-se pela proliferação de grupos e organizações ditos "islâmicos" - nunca pan-arabistas - que cometem atentados contra os Estados árabes mais explicitamente alinhados aos Estados Unidos e contra a própria potência hegemônica do pós-Guerra Fria e seus aliados, reivindicando, assim, o papel de libertadores dos povos árabes-islâmicos. Ou seja, na busca por assegurar a sobrevivência de seus regimes, os líderes árabes acabaram por abrir as portas da região para mais um questionador da legitimidade das lideranças árabes: o fundamentalismo islâmico.

É difícil vislumbrar, hoje, a possibilidade de construção de um efetivo projeto de integração política e econômica intra-árabe. O mais provável é que as tensões entre a ingerência norte-americana no Mundo Árabe e a resposta do fundamentalismo islâmico ditem os caminhos políticos da região nos próximos anos. A ironia envolvida nessa situação é que a promoção do ideal nacionalista árabe, mesmo que com seu significado conceitual alterado para que a unificação 
territorial dos Estados árabes ceda lugar para a integração política entre eles, revela-se como a melhor alternativa para os caminhos da subordinação e da regressão que se apresentam hoje.

\section{Notas}

1. Os termos "nacionalismo árabe", "arabismo" e "pan-arabismo" são utilizados, neste trabalho, como sinônimos. Esta sinonímia está de acordo com a literatura atual sobre o Mundo Árabe, na medida em que Barnett (1998) e Hudson (1999) usam os conceitos de "nacionalismo árabe" e "arabismo" como sinônimos; já Alnasrawi (1991) faz uso dos termos "nacionalismo árabe" e "pan-arabismo" sem grandes distinções; e, por fim, Hourani (2005) discute os conceitos de "nacionalismo árabe" e "arabismo", notando que o primeiro é mais ligado ao Islã do que o segundo, mas mesmo assim admitindo que "de acordo com a história, o desenvolvimento da nação árabe está muito ligado com o Islã, mas os árabes não são essencialmente uma nação muçulmana: se deixassem de ser muçulmanos, ainda seriam árabes. Assim, os cristãos de fala árabe são árabes no mesmo sentido dos muçulmanos, e podem ser árabes sem ter de renunciar a nada na sua tradição religiosa ou sem ter de aceitar a do Islã" (HOURANI, 2005, p. 328).

2. Neste trabalho, a região do OMNA refere-se apenas aos Estados dessas áreas cujo idioma oficial é o árabe e que são membros da Liga Árabe de Estados.

3. Esse termo deu origem à obra seminal de todo o debate acadêmico em língua inglesa sobre o nacionalismo árabe, The arab awakening: the story of the Arab National Movement, de George Antonius (1938).

4. “[...] a nação é sempre concebida como um companheirismo profundo e universal" (ANDERSON, 1989, p. 16).

5. Participaram Egito, Iraque, Líbano, Síria, Arábia Saudita, Iêmen e Transjordânia (esta última passou a denominar-se Jordânia em 1948).

6. São membros da Liga Árabe: Arábia Saudita, Argélia, Bahrein, Comores, Djibuti, Egito, Emirados Árabes Unidos, Iêmen, Iraque, Jordânia, Kuwait, Líbano, Líbia, Mauritânia, Marrocos, Omã, Palestina (Autoridade Nacional Palestina - ANP), Catar, Somália, Síria, Sudão e Tunísia. O Saara Ocidental ainda não é um país independente, estando sob tutela da ONU. 
7. "Instituição é um conjunto de regras (formais e informais) conectadas e persistentes que prescrevem regras de comportamento, constrangem atividades e moldam expectativas" (KEOHANE, 1989, p. 3 apud BARNETT, 1993, p. 272).

\section{Referências Bibliográficas}

ALNASRAWI, Abbas. Arab nationalism, oil and the political economy of dependency. New York: Greenwwod, 1991.

ANDERSON, Frederich. Nação e consciência nacional. Rio de Janeiro: Ática, 1989.

ANTONIUS, George. The arab awakening: the story of the Arab National Movement. London: H. Hamilton, 1938.

BARNETT, Michael N. Instituitons, roles and disorder: the case of Arab States System. International Studies Quarterly, v. 37, p. 271-296, 1993.

Sovereignty, nationalism and regional order in the Arab States System. International Organization, v. 49, n. 3, p. 479-510, 1995.

. Dialogues in arab politics. New York: Columbia University, 1998.

BUZAN, Barry; LITTLE, Richard; JONES, Charles. The logic of anarchy: neorealism to structural realism. New York: Columbia University, 1993.

GILPIN, Robert. Global political economy: understanding the international economic order. New Jersey: Princenton University Press, 2001.

GORE, Charles G. Regions in question. London: Methuen, 1984.

HOURANI, Albert. Uma história dos povos árabes. São Paulo: Companhia das Letras, 1994.

. O pensamento árabe na era liberal. Rio de Janeiro: Companhia das Letras, 2005.

HUDSON, Michael (Ed.). The Middle East dilemma: the politics and economics of arab integration. New York: Columbia University, 1999. 
HURREL, Andrew. O ressurgimento do regionalismo na política mundial. Contexto Internacional, v. 17, n. 1, p. 23-59, 1995.

KHADDURI, Majid. Towards an arab union: the League of Arab States. The American Political Science Review, v. 40, n. 1, p. 90-100, 1946.

KHALIDI, Rashid. Arab nationalism: historical problems in the literature. The American Historical Review, v. 96, n. 5, p. 1.363-1.373, 1991.

KORANY, Bahgat. The Arab World and the new balance of power in the New Middle East. In: HUDSON, M. (Org.). The Middle East dilemma: the politics and economics of arab integration. New York: Columbia University. 1999. p. 35-59.

LEAGUE OF ARAB STATES. Text of the pact of the Arab League. The American Journal of International Law, Washington, v. 39, n. 4, p. 266-272, Oct. 1945. Supplement.

SILVA, Guilherme A.; GONÇALVES, Williams. Dicionário de Relações Internacionais. Barveri: Manole, 2005.

WALTZ, Kenneth N. Theory of International Politics. New York: Random House, 1979. 


\section{Silvia Ferabolli}

\section{Resumo}

\section{Relações Internacionais do Mundo Árabe (1954-2004): Os Desafios para a Realização da Utopia Pan-arabista}

Desde a formação do Sistema Árabe de Estados, na esteira do processo de descolonização, a retórica do nacionalismo árabe tem sido o pano de fundo sobre o qual as relações políticas intra-árabes se desenvolveram. Contudo, as relações que se estabelecem entre os Estados árabes estão muito aquém da unidade, tendo se caracterizado mais pela desintegração. A literatura sobre a integração política no Mundo Árabe aponta diversos fatores envolvidos no aparente contra-senso representado pelo discurso unificador nacionalista árabe e na ausência de integração na região. Esses fatores foram analisados neste artigo, em diferentes períodos selecionados para estudo - a saber: 1954-1973, 1973-1990 e 1991-2004 -, tendo como referencial teórico o realismo estrutural, conforme proposto pela Escola Inglesa de Relações Internacionais. Na tentativa de responder ao questionamento que guiou essa pesquisa - o que condiciona o Mundo Árabe a viver uma permanente fragmentação, a despeito de todo o discurso unificador do arabismo? -, buscou-se identificar quais desses fatores apontados pela literatura sobre integração no Mundo Árabe tiveram um peso relativo maior para o fenômeno não integrativo intra-árabe, no que se concluiu que apenas a falta de complementaridade econômica regional não teve um papel relevante para a ausência de integração política intra-árabe entre os anos de 1954 e 2004.

Palavras-chave: Mundo Árabe - Pan-arabismo - Sistema Árabe de Estados - Integração Política - Realismo Estrutural 


\title{
Abstract
}

\section{International Relations of the Arab World (1954-2004): The Challenges for the Achievement of Pan-arab Utopia}

\begin{abstract}
Since the creation of the Arab State System in the wake of the decolonization process, the rhetoric of arab nationalism has been the background over which the political relations have been developed among the arab states. However, these relations are far from achieving unity, and can be characterized more by the desintegration. The literature on political integration in the Arab World points several factors related to the apparently contraditory idea represented by the unifying arab nationalism speech and the abscence of integration in the region. These factors were analysed in this research in different periods selected to be studied: 1954-1973, 1973-1990, and 1990-2004. As theoretical reference, it was used the structural realism proposed by the English School of International Relations. In the attempt to answer the question that guided this research what does condition the Arab World to live in a permanent fragmentation despite all the unifying arabist speech? - it was sought to identify which of theses factors pointed by the literature about integration in the Arab World had a greater role for the non-integrative arab phenomenon. It was revealed that only the lack of regional economic complementarity did not have a significant role for the absence of intra-arab political integration between the years 1954 and 2004 .
\end{abstract}

Keywords: Arab World - Pan-arabism - Arab State System - Political Integration - Structural Realism 